\title{
Efeitos territoriais de grandes empreendimentos urbanos: o território da feira central de Campo Grande e as transformações no espaço
}

\section{Territorial effects of large urban developments: the territory of the central of campo grande and the big changes in space}

Marcela Paiva da Silva - Mestre em Meio Ambiente e Desenvolvimento Regional pela Anhanguera Educacional (2011). Professora tutora à distância no curso Tecnológico em Logística no Centro de Educação à Distância da Universidade Anhanguera/Uniderp. E-mail: marcela_margarida@ hotmail.com

Mercedes Abid Mercante - Mestre em Ciências Humanas pela Faculdade de Filosofia Ciências e Letras do Sagrado Coração de Jesus (1982) e doutora em Geografia Física pela Universidade de São Paulo (1994). Professora titular da Universidade para o Desenvolvimento do Estado e da Região do Pantanal. E-mail: mercante@terra.com.br

Vicente de Paulo da Silva - Licenciado em Geografia pela Universidade Federal de Uberlândia (1988), mestre em Geografia Humana pela Universidade de São Paulo (1995) e doutor em Geografia pela Universidade Federal do Rio de Janeiro (2004). Professor adjunto no Instituto de Geografia da Universidade Federal de Uberlândia. E-mail: vicentepht@hotmail.com

\section{Resumo}

São inúmeras as transformações no espaço territorial causadas pelo avanço da construção e instalação de grandes empreendimentos. Em nome do desenvolvimento econômico, a desconstrução e reconstrução de territórios são processos que influenciam na identidade cultural da população envolvida, como, por exemplo, na Feira Central de Campo Grande/ MS, a qual foi submetida à mudança de endereço, permitindo novos aspectos de territorialidade. Por meio de idas a campo, observação, entrevistas e aplicação de questionários, foi possível analisar as alterações provenientes de tal mudança, ocasionadas na vida dos atores envolvidos. Dentre as alterações, salientam-se também as ocorridas no uso e ocupação do solo, verificadas por meio de imagens.

\section{Palavras-chave}

Campo Grande. Grandes empreendimentos. Feira Central. Território. Identidade.

\begin{abstract}
There are numerous changes in the territorial space caused by the advance of the construction and installation of large enterprises. In the name of economic development, deconstruction and reconstruction of territories are processes that influence the cultural identity of the population involved, such as in the Feira Central of Campo Grande / MS, which was submitted to the address change, allowing new aspects of territoriality . Through field trips, observation, interviews and questionnaires, it was possible to analyze changes from such a change caused in the lives of those involved. Among the changes, stress is also occurring in the use and occupation of land, verified by means of images.
\end{abstract}

\section{Keywords}

Campo Grande. Large Enterprises. Feira Central of Campo Grande. Territory. Identity. 


\section{INTRODUÇÃO}

O processo de globalização da economia, aliado à intensificação do uso dos recursos naturais, e mesmo industriais, vêm transformando diversas paisagens e espaços territoriais no Brasil, ou seja, destruindo antigos territórios e reconstruindo novos em seus estados e municípios. Em Campo Grande, capital do estado de Mato Grosso do Sul, a inserção de grandes empreendimentos é inevitável, devido ao seu significativo crescimento econômico no cenário nacional. Segundo dados estatísticos do estado, as atividades de agricultura, silvicultura, criação de animais e extrativismo vegetal, somaram 54.912 empregos diretos em 2005 e apresentou um aumento no ano de 2008 para 58.549 empregos, de acordo com a Secretaria do Estado de Meio Ambiente, do Planejamento, da Ciência e da Tecnologia (2009, p. 31).

Com posição geográfica privilegiada, o estado de Mato Grosso do Sul quase dobrou seu produto interno bruto em cerca de cinco anos, pois, em 2002, seu Produto Interno Bruto (PIB) foi de 15.154 milhões, passando para 28.121 milhões em 2007 (SEMA, 2009, p. 42). Sendo a soja e o milho seus principais produtos de produção agrícola, o estado também se destaca no turismo, em que vários municípios, como Bonito, ganharam notoriedade nacionalmente.

Esse crescimento econômico pelo qual o estado de Mato Grosso do Sul passa atualmente, serve de palco para as inúmeras transformações relacionadas ao seu uso e ocupação do solo. Contudo, na maioria das vezes, essa dinâmica ocasiona impactos na vida da população, que de alguma forma se insere nos processos de construção, instalação e operação de grandes empreendimentos tanto em áreas rurais quanto em urbanas.

As mudanças espaciais causadas por empreendimentos de grande porte podem atingir vários aspectos, como econômicos, políticos, sociais e ambientais. Dentro de tais aspectos, cita-se a mudança significativa na vida das pessoas envolvidas, além de seus sentimentos atribuídos ao espaço territorial. Tal relação é definida como territorialidade; processo pelo qual passou a Feira Central de Campo Grande.

Neste sentido, a Feira passou pelo que aqui se chamará de um processo de desterritorialização, o qual, segundo Ianni (1992, p. 94), "manifesta-se tanto na esfera da economia como na da política e cultura. Todos os níveis da vida social, em alguma medida são alcançados pelo deslocamento ou dissolução de fronteiras, raízes, centros decisórios, pontos de referência" - e, consequentemente, pela sua reterritorialização, que, segundo Castilho e Chaparro (2009, p. 383), "é a forma encontrada por grupos híbridos de reconstruírem sua história, de estabelecer 
novamente as relações sociais, simbólicas, econômicas, políticas e efetivas no espaço pelo qual eles (re)conquistaram". No caso da Feira Central de Campo Grande, ao sair de um lugar já tradicional para o campo-grandense e se instalar em outro local, criou-se um novo território.

A problemática proposta neste trabalho apresenta uma discussão envolvendo o atual estágio de modernização do espaço e as consequências das decisões tomadas pelo poder público ou, ainda, por ações de particulares, a partir de sua mudança de endereço.

O processo de modernização, muitas vezes comandado por grandes empresários e/ou investidores locais ou regionais, tem promovido profundas alterações na dinâmica dos espaços urbanos ou rurais. Tais processos têm sido promovidos por uma política de incentivos aos grandes empreendimentos, os quais alteram a fisionomia das cidades, quer sejam pequenas, médias ou grandes.

Esses empreendimentos são executados, em sua maioria, com um discurso que visa os interesses de pessoas de poder aquisitivo alto, mas que, na verdade ocultam seus verdadeiros propósitos, ao disseminarem notícias de que sua execução vai tirar o lugar de uma condição de desenvolvimento, até então considerada estagnada, para alçar melhorias na qualidade de vida junto à comunidade local.

Assim, entende-se que o discurso do progresso esteja imbuído de uma estratégia para garantir a realização de grandes obras, negando os efeitos sociais e espaciais, à medida que toma a população envolvida como sendo o verdadeiro objetivo da obra. Isto significa que falar de grandes empreendimentos é o mesmo que falar de uma complexa teia de relações, em que os interesses divergentes entre elite e população como um todo entram numa disputa na qual acaba prevalecendo a vontade dos mais fortes. Como efeito dessas decisões, tem-se um amplo processo de ruptura da história dos lugares e das pessoas. Símbolos podem ser destruídos, no que também pode ser chamado de um movimento contraditório de destruição e reconstrução, pois, à medida que um território é destruído para dar lugar a outro, o mesmo deverá ser reconstruído em outro lugar, mas nunca será o mesmo de antes.

São perceptíveis, não apenas na cidade de Campo Grande, mas em todo o país, inúmeras mudanças relacionadas à população envolvida nesses processos. Citam-se alguns impactos que podem ocorrer sobre a população residente e do entorno, como a alteração na rotina dos moradores, de hábitos e até mesmo mudanças culturais, as quais, na maioria das vezes, são consideradas impossíveis de serem recriadas. Diante disso, questiona-se se essas rupturas seriam consideradas catastróficas, por não permitirem a recriação de hábitos ou 
símbolos já tradicionais ou se o grupo poderia reconstruir, de certa maneira, a vida como era antes da implantação do projeto? Seria possível falar de novos hábitos, uma nova cultura ou uma mistura de ambos?

A desterritorialização e a reterritorialização são processos que ocorrem quando há mudanças em termos territoriais, como é o caso da Feira Central de Campo Grande. Essa mudança territorial não se restringe apenas ao uso e ocupação de novos espaços territoriais, mas também, de alguma forma, incide diretamente nas pessoas. De fato, incide em algo chamado de identidade territorial, a qual, segundo Haesbaert (2004 apud BEZERRA 2007, p. 64): “[...] trata-se de uma identidade em que um dos aspectos fundamentais para a sua estruturação está na alusão ou referência a um território, tanto no sentido simbólico quanto concreto".

Outro aspecto pertencente ao território é a memória das comunidades instaladas em determinados territórios, pois sua característica é relevante para as futuras gerações advindas de intervenções do sistema econômico atual. Segundo Le Goff (1992, p. 337), “a memória é um elemento essencial do que se costuma chamar de identidade, individual ou coletiva, cuja busca é uma das atividades fundamentais dos indivíduos de hoje, na febre e na angústia”.

A Feira Central de Campo Grande foi fundada em 04/05/1925, pelo Decreto de $n^{\circ} 17$, por meio do Intendente Municipal Arnaldo Estevão Figueiredo. Hoje, localiza-se na Esplanada da Ferrovia, e tem como destaque o tradicional espetinho, feito como churrasco de carne bovina, servido com a mandioca amarela da terra e o sobá, assim como seu horário de funcionamento, pois a Feira Central funciona no período noturno, diferenciando-se das demais feiras espalhadas pelo país. Outras opções são o artesanato e o comércio de produtos típicos.

A Feira Central de Campo Grande empregava, no ano de 2010, cerca de 1.180 funcionários com vínculo empregatício, distribuídos em 198 lojas, 120 quiosques e 28 restaurantes, segundo nomenclatura utilizada e dados fornecidos pela Associação da Feira Central e Turística de Campo Grande (AFECETUR). De acordo com dados da Prefeitura Municipal da cidade, os feirantes foram estimulados a regulamentar suas atividades dentro do espaço da Feira, mediante o acesso facilitado. Tal medida possibilitou a abertura de alvarás, em um total de 346 constituídos.

Por meio da memória e identidade territorial a ser analisada na Feira Central, as relações sociais ali existentes e decorrentes podem se fortalecer de alguma maneira. Através da representatividade atribuída ao território, aliada à sua simbologia, por parte dos atores envolvidos, seria possível valorar esse bem 
como item importante e significativo na vida das pessoas da cidade de Campo Grande.

O presente trabalho tem como objetivo analisar os processos relacionados à territorialidade e as alterações ocorridas no novo espaço ocupado pelo empreendimento da Feira Central de Campo Grande, no estado de Mato Grosso do Sul, cuja sede foi alterada em função de uma decisão que exigia a sua relocalização.

\section{REVISÃO DE LITERATURA}

Uma das características perceptíveis do sistema capitalista é a inserção de grandes empreendimentos em todo o território nacional, como forma de garantir o chamado progresso. Por meio de investimentos nacionais e estrangeiros, o poder público estimula, apoia e viabiliza obras significativas, com o intuito de aumentar o potencial econômico do país. Em sua maioria, tais empreendimentos ocupam extensas áreas de terra e, com isso, modificam não apenas a paisagem, mas também a economia local e a vida da população do entorno. Neste sentido, é passível o questionamento quanto ao significado da palavra Progresso: crescimento econômico? E então outra questão se faz importante: crescimento econômico, de quem ou em nome de quem?

Em relação à mudança expressiva que ocorre no âmbito dos aspectos sociais e de uso e ocupação do solo - o foco da presente pesquisa, com a implantação de uma grande obra, é possível que ocorram pontos divergentes entre a função da obra em si e as consequências disso na rotina das pessoas.

Os grandes projetos contribuíram decisivamente para despertar o demônio da política, adormecido na alma dos humilhados e desvalidos da terra, que põe em questão mais do que esses projetos - põe em questão o direito de propriedade (tal como está formulado, em função dos interesses do grande capital rentista e especulativo) e as relações de poder, de que os grandes projetos são o produto corrosivo (MARTINS, 1993, p. 82) .

$\mathrm{Na}$ maioria das vezes, o povo é surpreendido pelos grandes empreendimentos, pois não esperam que suas vidas venham a ser ameaçadas pelo progresso, e geralmente ficam à mercê de negociações daqueles que detêm o poder. De fato, o lucro é um dos pontos importantes na decisão por uma obra de grande porte, sejam elas para o abastecimento energético, para o uso de matérias-primas, para a fabricação de combustíveis, para o aumento do consumo no comércio, entre outros. Todas trazem, de certa forma, a "bandeira" de uma vida nova, em suma, do desenvolvimento econômico, da geração de empregos e da distribuição de renda. 
Geralmente, nas negociações que norteiam os grandes empreendimentos, as questões que pertencem ao povo são as menos argumentadas e discutidas. As necessidades econômicas, a questão da perda e mudança de território que acometem a população envolvida são vistas como menos importantes ou até insignificantes por parte dos governantes e investidores, diante das consequências positivas da obra, segundo as suas concepções.

A ligação de todo ser humano com seu espaço geográfico está de fato vulnerável a ações externas de cunho político-social de terceiros, variando de objetivos e formas para o seu uso. De fato, necessita-se de uma definição de território apropriada para a proposta de pesquisa em questão.

É essencial compreender que o espaço é anterior ao território. “O território se forma a partir do espaço, é o resultado de uma ação conduzida por um ator sintagmático (ator que realiza um programa) em qualquer nível” (RAFFESTIN, 1993, p. 143). O autor ainda complementa dizendo que o território, nessa perspectiva, é um espaço onde se projetou um trabalho, seja energia ou informação, e que, por consequência, revela relações marcadas pelo poder.

Se o espaço que se ocupa e, consequentemente, o território expressa poder, todos são poderosos em seus dignos domínios. Contudo, percebe-se que esse poder não pertence a todos, mas sim a uma minoria de mandantes, ocupantes de cargos ditos respeitosos, os quais, apoiados pelo atual sistema econômico, fazem uso de iniciativas de desenvolvimento econômico em prol de seus próprios interesses.

O poder expressado por Raffestin não pertence a todos, porém, o conceito de território se estende a mais aspectos, pois, de acordo com Santos e Silveira (2008, p. 19), por território entende-se geralmente a extensão apropriada e usada. Mas, o sentido da palavra territorialidade como sinônimo de pertencer a um território que nos pertence, esse sentimento de exclusividade e limite ultrapassa a raça humana e prescinde da existência de Estado. Ou ainda, é construído na complexidade entre o material e imaterial, funcional e simbólico.

Percebe-se que a territorialidade está ligada ao território. Raffestin (1993, p. 159) afirma que a vida é tecida por relações, e daí a territorialidade pode ser definida como um conjunto de relações que se origina num sistema tridimensional sociedade-espaço-tempo, em vias de atingir a maior autonomia possível, compatível com os recursos do sistema. A territorialidade pode ser entendida como algo abstrato, pois a ela pertence toda a simbologia ou as relações invisíveis atribuídas a um território.

Ao enfatizar o domínio das relações imateriais que prescindem de bases materiais, de acordo com Haesbaert (2006, p. 36), o território é visto, antes de 
tudo, como o espaço concreto em que se produzem ou se fixam os processos sociais. Entende-se, então, que as questões que norteiam a territorialidade são significativas em âmbito social, ou seja, fazem parte da vida das pessoas.

Os processos de desterritorialização podem ocasionar, dentre outros fatores, a mudança de valores por parte das pessoas envolvidas. Valores esses que incidem diretamente em suas culturas e, consequentemente, em suas identidades. Salienta-se uma desterritorialização do ponto de vista culturalista:

Percebida a partir de uma leitura do território como fonte de identificação cultural, referência simbólica que perde sentido e se transforma em um "não-lugar". Estes "não-territórios", culturalmente falando, perdem o sentido/o valor de espaços aglutinadores de identidades, na medida em que as pessoas não mais se identificam simbólica e afetivamente com os lugares em que vivem, ou se identificam com vários deles ao mesmo tempo e podem mudar de referência espacial-identitária com relativa facilidade (HAESBAERT, 2006, p. 93).

Todo processo de desterritorialização exige um processo de reterritorialização, ou seja, desconstruir e reconstruir territórios são ações presentes. Territórios são algo pertencente ao processo de globalização, que atua firmemente e avança cada vez mais sobre os espaços geográficos ainda disponíveis. Tais processos podem incidir diretamente nas identidades territoriais.

Atribuir sentimentos ao território consiste em adquirir uma identidade territorial. Segundo Costa (2005, p. 84), todos os processos de produção e manutenção de identidades sociais necessitam do suporte espacial, assim como o espaço geográfico é indissociável das ações sociais.

Percebe-se que as pessoas adquirem identidades territoriais a partir do espaço no qual vivem e ou se relacionam, que podem surgir e se desenvolverem também em ambientes urbanos, ou seja, nas cidades, devido ao volume de pessoas e territórios. Ainda de acordo com Costa (2005, p. 86), quanto maior a cidade, maior a diversidade social, pois ela agrega uma variabilidade de possibilidades de trabalho, de níveis de consumo, de papéis sociais e de proveniência de pessoas. Diante da variedade citada pelo autor, podem ocorrer formas diversificadas de identificação nos centros urbanos, fragmentando-se em classes, grupos, comunidades, entre outros.

As feiras livres são verdadeiros pontos ou referenciais de atração turística cultural, de lazer e de compras. Feira livre é uma entidade voltada para a comercialização variada de produtos, de acordo com as características econômicas de diversas regiões (LIMA FILHO et. al., 2008, p. 2). No Brasil, existem várias feiras tradicionais. 
Ao frequentar uma feira livre, é possível conhecer os traços culturais, os costumes, a comida e o comportamento das pessoas de uma localidade. Em quase todos os roteiros turísticos históricos-culturais sugeridos por agências de viagens, na atualidade, existe a indicação de uma feira livre. Várias cidades brasileiras possuem espaços livres, em feiras, demonstrando a cultura local.

Também como opção de lazer e entretenimento, as feiras livres representam um ponto de encontro e um local de convivência para as pessoas. Com isso, expressam aspectos do território. A questão da territorialidade implica consequências em sua implantação e operação, pois afeta não só os demais empreendimentos na redondeza, mas também a população do entorno, os consumidores locais e as pessoas que dela tiram seu sustento.

\section{MATERIAL E MÉTODOS}

A tradicional Feira Central antiga da cidade, considerada um Centro Comercial não planejado (Figura 1), popularmente conhecida como "feirona", era composta por 377 barracas, ocupando uma área de aproximadamente 2,1 mil metros quadrados (LIMA FILHO et. al., 2008, p. 6). Era localizada na Rua Abrão Julio Rahe com a Rua José Antônio. Além de frutas, legumes e verduras, os visitantes também podiam adquirir produtos eletrônicos, roupas e artesanatos. Recebia cerca de 20 mil pessoas às quartas-feiras e aos finais de semana, segundo a Prefeitura Municipal de Campo Grande (2010). Contudo, após decisão em conjunto do executivo municipal com o comprador do terreno paralelo, onde a Feira ocorria, a mesma foi deslocada para um novo endereço.

Figura 1: Feira Central de Campo Grande no endereço antigo.

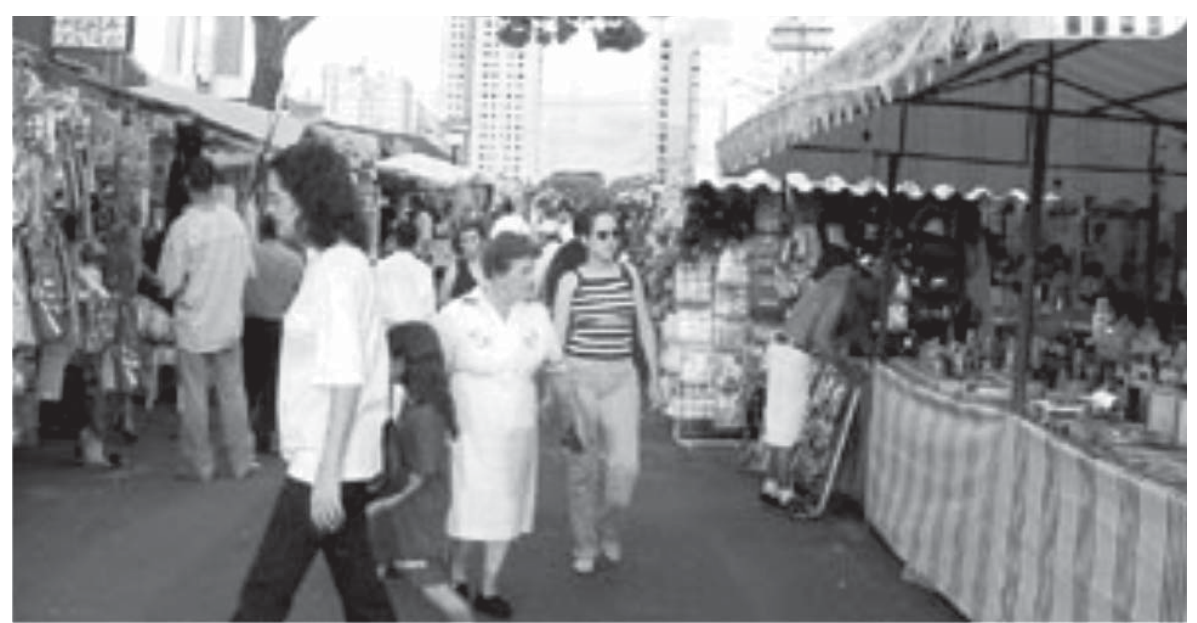

Fonte: Arquivo pessoal.

Novos Cadernos NAEA •v. 15 n. $2 \cdot$ p. 85-109 • dez. 2012 
A necessidade da mudança de endereço da Feira Central ocorreu devido à compra de um terreno até então vazio, na Av. Mato Grosso, uma das avenidas mais movimentadas e populares da cidade de Campo Grande. O espaço territorial foi comprado pela Igreja Universal do Reino de Deus, com o objetivo de se construir o maior templo religioso da cidade. Diante disso, percebe-se que houve grande interesse por parte da instituição compradora do terreno onde se localizava a Feira Central de Campo Grande, que a mesma fosse transferida para outro espaço territorial.

Após negociação com a Prefeitura Municipal de Campo Grande, definiuse o novo endereço da Feira Central. A mudança ocorreu no ano 2004, quando a estrutura física da obra da nova Feira ficou pronta. Diante disso, os feirantes tiveram que se transferir para seu novo destino de trabalho, juntamente com todo o seu público de visitantes. Contudo, há registros, em documentos restritos da Prefeitura Municipal, de que houve reuniões com todos os envolvidos, mediadas por representantes da Prefeitura, com o intuito de "amenizar" os efeitos dessa mudança e gerar acordo.

Atualmente a Feira está instalada na esplanada da antiga estação ferroviária, localizada na Rua 14 de Julho, número 3351 (Figura 2), sendo considerada um centro comercial planejado (Figura 3), com acesso pela Rua 14 de Julho e também pela antiga Vila dos Ferroviários, com amplo estacionamento e moradores no entorno. O local abriga barracas de alimentação pronta para consumo, hortifrutigranjeiros, armarinhos, artesanato e importados. O centro comercial ocupa uma área de $13 \mathrm{mil} \mathrm{m}^{2}$, sendo 8,5 mil $\mathrm{m}^{2}$ cobertos. A nova área conta com estrutura sanitária adequada, redes de água e esgoto, iluminação e espaço para eventos. A área de circulação de visitantes, que anteriormente era de quatro metros de largura, passou para seis metros PLANURB, 2005). 
Figura 2: Localização da Feira Central em Campo Grande/MS.

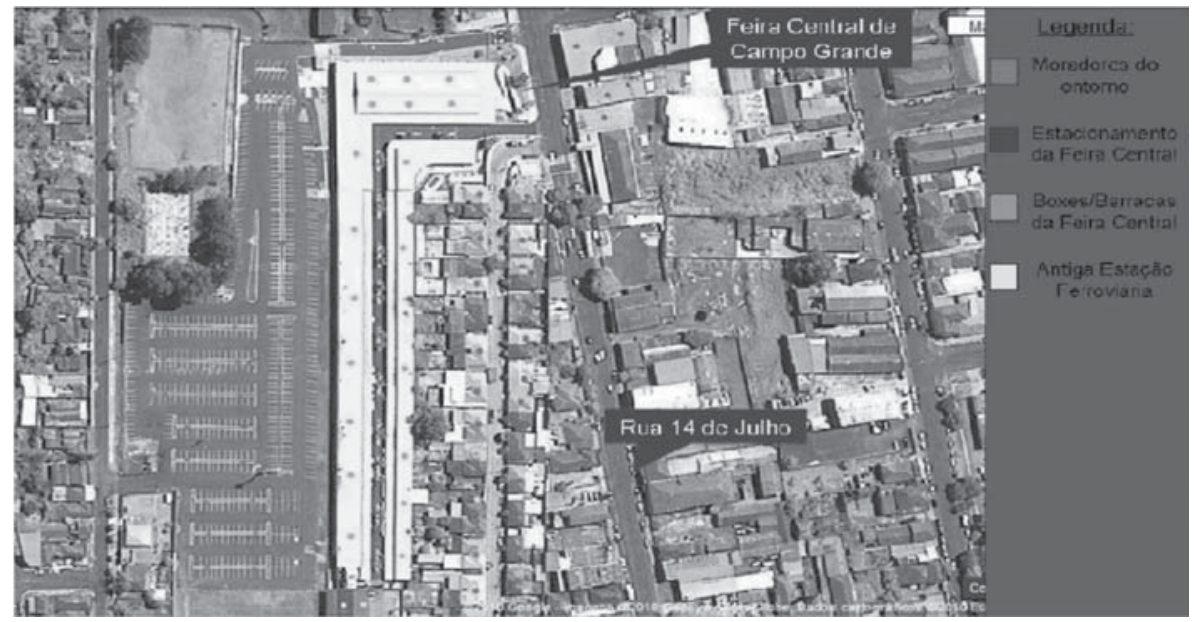

Fonte: Google Imagens: http:/maps.google.com.br às 12:30 horas do dia 27/09/2010.

Figura 3: Feira Central de Campo Grande no atual endereço.

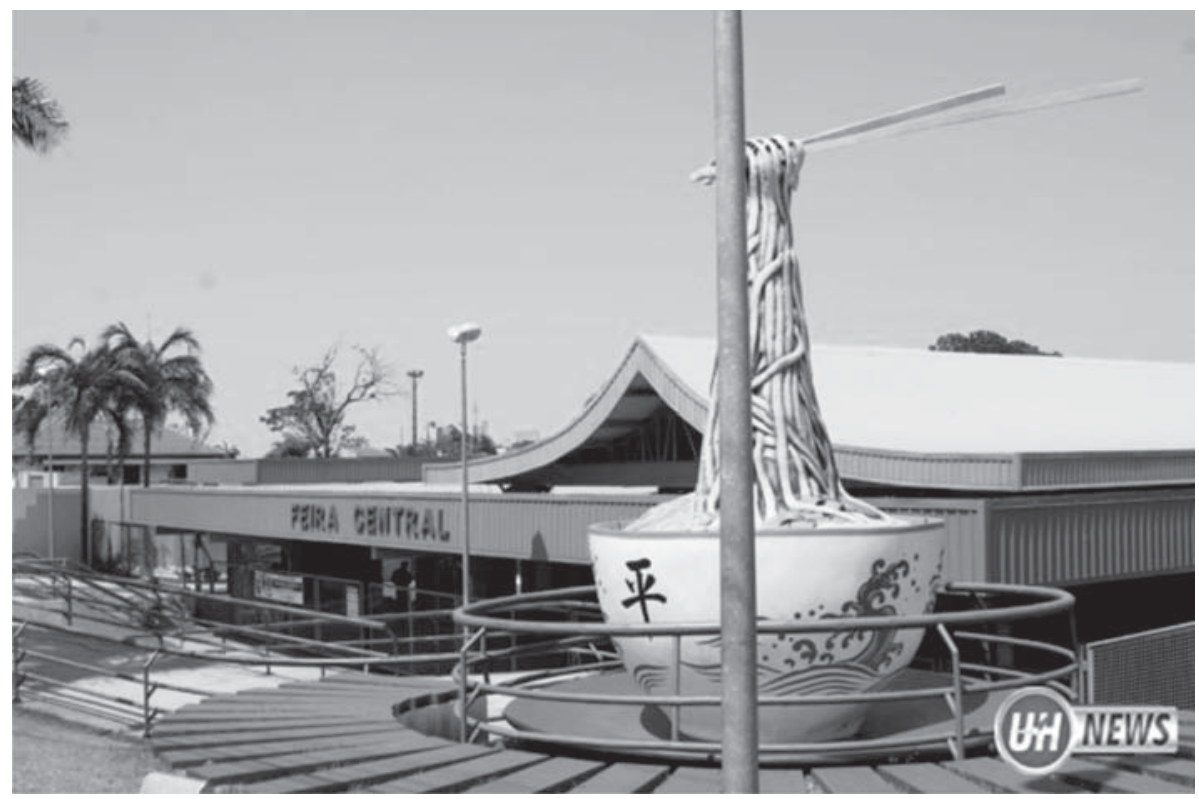

Fonte: Jornal VH NEWS, 2009.

Mediante as transformações de uso e ocupação do solo, oriundos da mudança de endereço da Feira Central de Campo Grande, para analisar a existência de representatividade ligada às questões de identidade e cultura do Novos Cadernos NAEA • v. 15 n. 2 • p. 85-109 • dez. 2012 
empreendimento, foi necessário levantamento bibliográfico prévio e leituras aprofundadas sobre ao tema.

A pesquisa caracterizou-se como de campo, a qual consiste na observação de fatos e fenômenos tal como ocorrem espontaneamente, na coleta de dados a eles referentes e no registro de variáveis que se presume relevantes para analisá-los (LAKATOS; MARCONI, 2009, p. 175). E, ainda, abrangeu aspectos quantitativo-descritivos, os quais propositaram investigações de pesquisa empírica, cuja principal finalidade foi o delineamento ou análise das características das consequencias ocorridas.

Como instrumentos para a coleta de dados, optou-se por questionários semiabertos (Anexo 1), elaborados por meio do software Sphinx, versão 5.0, voltados aos três tipos de públicos: 1) frequentadores (consumidores locais e/ ou turistas), sendo 40 questionários respondidos para os consumidores locais e 20 para os turistas; 2) colaboradores (funcionários e/ou feirantes), sendo 40 questionários respondidos; e 3) população do entorno da Feira Central, sendo 20 questionários respondidos. Contudo, ressalta-se que não foram traçados os perfis socioeconômicos dos públicos, devido ao grande número de atores envolvidos e a grande rotatividade de pessoas que usufruem de alguma forma da Feira Central semanalmente.

Registrou-se um número de 120 questionários respondidos, abrangendo os consumidores locais, os turistas, os feirantes e os moradores do entorno. $\mathrm{O}$ questionário que difere dos demais foi o aplicado aos turistas, devido à falta de conhecimento e informação quanto à mudança de endereço da Feira Central de Campo Grande. A última questão do questionário de todos os públicos citados foi aberta, para melhor avaliação e análise dos depoimentos.

Além dos questionários, a presente pesquisa contou com a contribuição importante e válida por parte da Prefeitura Municipal de Campo Grande, especificamente a Secretaria Municipal de Meio Ambiente e Desenvolvimento Urbano (SEMADUR), à qual responde a Associação da Feira Central e Turística de Campo Grande (AFECETUR). Foram feitas visitas aos órgãos citados, a fim de se obter esclarecimentos quanto ao funcionamento e administração da Feira Central.

A fim de analisar as alterações na paisagem no novo endereço ocupado pela Feira Central, utilizou-se do software Google Earth, versão 6.0. A partir do uso das imagens do território, de 2002, 2006 e 2009, antes, durante e após a ocupação do empreendimento, respectivamente, foi possível a visualização e percepção das alterações de paisagem e as novas ocupações e uso de solo em questão. 
Nos aspectos que norteiam a territorialidade modificada através da implantação da Feira Central de Campo Grande em seu novo endereço, foi possível avaliar a significância e as consequências ocorridas na rotina dos moradores e dos comerciantes do entorno, após a instalação da mesma na região. É, sem dúvida, a partir das mudanças ocorridas no território que novos valores surgem no entorno imediato. A mudança se materializa com os novos territórios que surgem, tais como: novos locais para estacionamento, para eventos, comercialização e lazer, além do valor simbólico atribuído ao empreendimento.

\section{RESULTADOS E DISCUSSÃO}

Em Campo Grande, a feira livre existe há cerca de 80 anos. Instituída em 1925, para suprir uma crise de abastecimento de gêneros alimentícios, a "Feirona" cresceu e assumiu um lugar definitivo na vida da cidade e é um de seus principais pontos turísticos (RODRIGUES; FORATO, 2002, p. 14).

Em dezembro de 2004, a tradicional Feira Central de Campo Grande passa a se apresentar com uma nova infraestrutura, em uma nova localização. $\mathrm{Na}$ feira atual, ou melhor, no centro comercial planejado, os feirantes e visitantes contam com melhor estrutura sanitária, redes de água e esgoto, iluminação, espaço para eventos e uma área de circulação maior, quando comparada à anterior.

A feirona sofre grande influência da comunidade Okinawa, que possui forte presença na culinária local. Campo Grande, capital do estado de Mato Grosso do Sul, possui a maior colônia de imigrantes okinawanos do Brasil, depois de São Paulo. São pelo menos 1.800 famílias originárias de Okinawa (TEIXEIRA, 2006, p. 28).

Ao se considerar a gastronomia como uma forma de manifestação cultural e representativa de um grupo ou mesmo de uma nação, observa-se em Campo Grande a presença marcante do sobá.

O sobá é um dos pratos típicos da gastronomia campo-grandense, adaptado da culinária oriental pelos imigrantes chegados em 1908, da província de Okinawa, arquipélago de influência chinesa, na região sul do Japão. Nessa cidade, tradicionalmente às vésperas do ano novo, as famílias se reuniam para degustar esse tradicional prato, feito de macarrão de trigo sarraceno, o toshikoshisoba (MARQUES, 2009). Tornou-se, assim, um prato típico de Campo Grande, amplamente divulgado. É a principal atração da Feira Central da cidade, que anualmente promove o Festival do Sobá, em parceria com a Prefeitura Municipal.

Entretanto, o sobá campo-grandense tem seu diferencial, que não é encontrado no original e nem nos demais núcleos de imigrantes do país, sendo 
uma especificidade da cultura local. Diante disso, o sobá foi registrado como o primeiro bem imaterial de seu Patrimônio Histórico e Cultural, por meio do Decreto Municipal no 9.685, de 18 de julho de 2006 (DIOGRANDE, 19/07/06). É necessário atribuir relativa importância à imigração japonesa no país, e, consequentemente, na cidade de Campo Grande.

A imigração japonesa no Brasil teve seu início com a chegada do navio Kasato Maru no porto da cidade de Santos, no dia 18 de junho de 1908. Vindo do porto de Kobe, o navio trouxe, em uma viagem de 52 dias, os 781 primeiros imigrantes, sob contrato entre Brasil e Japão. A bordo do Kasato Maru estava um povo que trazia, além da bagagem, uma cultura milenar (OLIVEIRA, 2006, p. 9).

Entre 1910 e 1935, muitos imigrantes foram contratados para trabalhar nas fazendas de café, formando assim vários núcleos e colônias por todo o país. Esses núcleos proliferaram em diversas localidades entre 1925 e 1935, quando se alcançou o maior número de imigrantes japoneses entrados no Brasil, num total de 140.000 (RODRIGUES; FORATO, 2002, p. 11)

Com a Primeira Guerra Mundial, o fluxo diminuiu significativamente, restabelecendo-se após 10 anos, em 1959. Segundo dados da Embaixada Japonesa divulgados em 2008, em 1996 eram 89.005 japoneses no Brasil. Em 2006, conforme o último censo, o número de nipônicos no país era de 64.802 uma diferença de quase 30\%. Entre o período de 1996 e 2006 houve queda em todos os anos.

O processo imigratório foi de extrema importância para a formação da cultura brasileira. Esta foi, ao longo dos anos, incorporando características dos quatro cantos do mundo. São várias as influências trazidas pelos imigrantes, que se tem um leque enorme de resultados: o idioma português, a culinária italiana, as técnicas agrícolas alemãs, as batidas musicais africanas e muito mais. Graças a todos eles, vivemos em um país de múltiplas cores e sabores. Um povo com uma cultura diversificada e de grande valor histórico (OLIVEIRA, 2006, p. 43).

Por meio da construção da Estrada de Ferro Noroeste, os japoneses se dirigiram para o estado de Mato Grosso do Sul. Diante de trabalho árduo, esses imigrantes começaram a exercer paralelamente a atividade de agricultura de subsistência nas terras da cidade de Campo Grande. Compraram sítios onde produziram hortaliças para vender em feiras livres, abriram bares para vender a pinga fabricada. Enfim, praticaram todas as atividades que seu pequeno capital permitia, enquanto criavam seus filhos. Dessa maneira, construíram as fundações da hoje próspera comunidade nipo-brasileira no estado de Mato Grosso do Sul (OLIVEIRA, 2006, p. 43). 
Além da presença da comunidade japonesa, foram muitos os apontamentos feitos pelos públicos abordados pela pesquisa, os quais serão discutidos e demonstrados nos tópicos seguintes. Ressalta-se que os questionários foram aplicados no mês de outubro/2010, no período da manhã, para os moradores do entorno e no período da noite, para os consumidores locais, turistas e feirantes. Os apontamentos serão descritos por grupo, e, por fim, serão apresentadas as imagens da análise de alterações na paisagem.

\subsection{CONSUMIDOR LOCAL}

Para a maioria dos consumidores locais, a mudança da Feira Central foi positiva devido às melhorias em infraestrutura e higiene. Porém, 33,3\% apontaram a mudança como negativa, pois alegaram a perda de algumas características importantes das feiras livres, como a falta da vendida de grãos na modalidade a granel (Figura 4).

Figura 4: A mudança do endereço da Feira Central para o consumidor local.

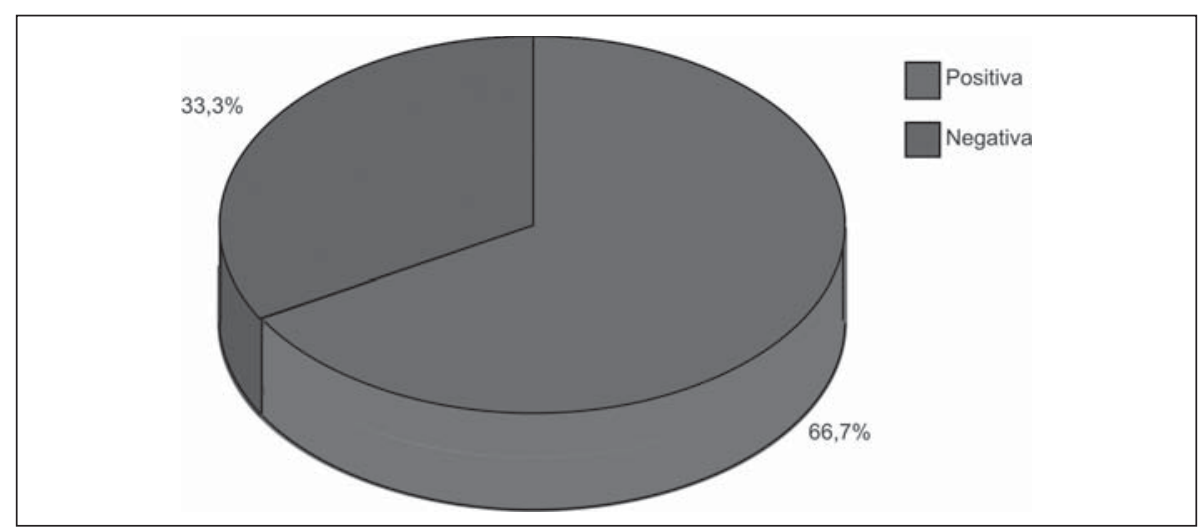

Fonte: Pesquisa direta.

A Figura 5 mostra a representatividade do empreendimento para o consumidor local. Um dos aspectos que mais se destacou foi o de a Feira Central fazer parte da identidade cultural da cidade. Diante disso, pode-se dizer que tanto os consumidores que afirmaram ser negativa a mudança de endereço quanto os que consideraram positiva, atribuem à Feira certa representatividade em suas vidas. A opção representada em $0 \%$ no mesmo gráfico corresponde à opção de o empreendimento não possuir importância nem representatividade alguma para a cidade. Esta opção não foi assinalada por nenhum dos consumidores locais abordados. 
Figura 5: A Feira Central para os consumidores locais.

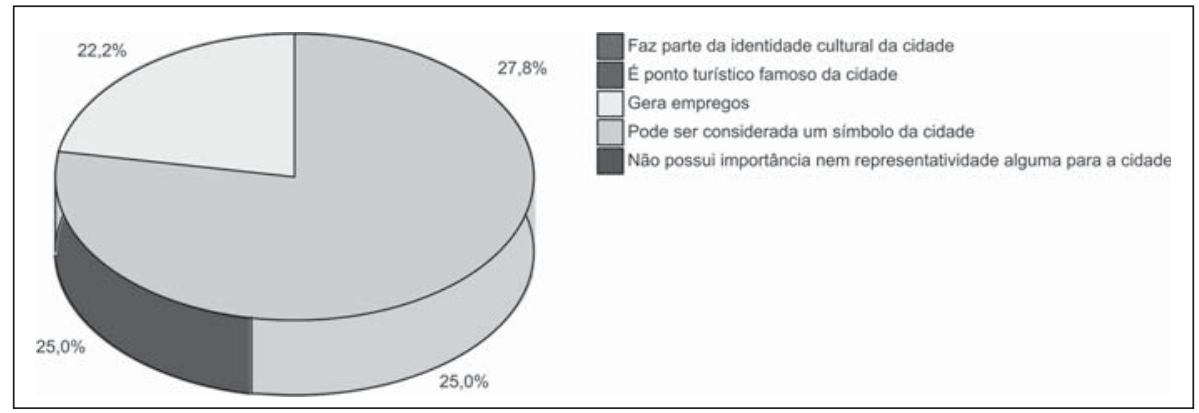

Fonte: pesquisa direta.

A última questão do questionário aplicado consistiu em indagar a importância da Feira para os consumidores locais. Os mesmos expressaram que além de ser significativa para a identidade cultural da cidade de Campo Grande, a mesma é espaço importante de convivência e interação entre as pessoas, ou seja, para se reunir com a família e amigos. As opções de lazer, diversidade de produtos e a procura por comida típica também foram salientados.

\subsection{TURISTA}

Segundo a Presidente da AFECETUR, a Feira Central costuma receber 5 mil visitantes aos sábados, exceto em dias de festas, como o Festival do Sobá e a Festa do Peixe, chegando a quase dobrar esse número, dentre os quais os turistas marcam presença, em busca de diversos itens e por vários motivos.

Conforme mostra a Figura 6, 29,4\% dos turistas abordados disseram que o motivo de sua visitação é a comida típica, o que torna ainda mais expressivo o significado e importância da culinária japonesa, principalmente o sobá, na cultura do campo-grandense. E, ainda, o fator comida típica pode ser usado para evidenciar o potencial turístico da Feira Central, além de incentivar os moradores locais da cidade de Campo Grande a valorizarem essa cultura, seja como identidade cultural, geração de renda, pelo turismo regional ou por seu simbolismo. 
Figura 6: Motivo da visitação dos turistas da Feira Central.

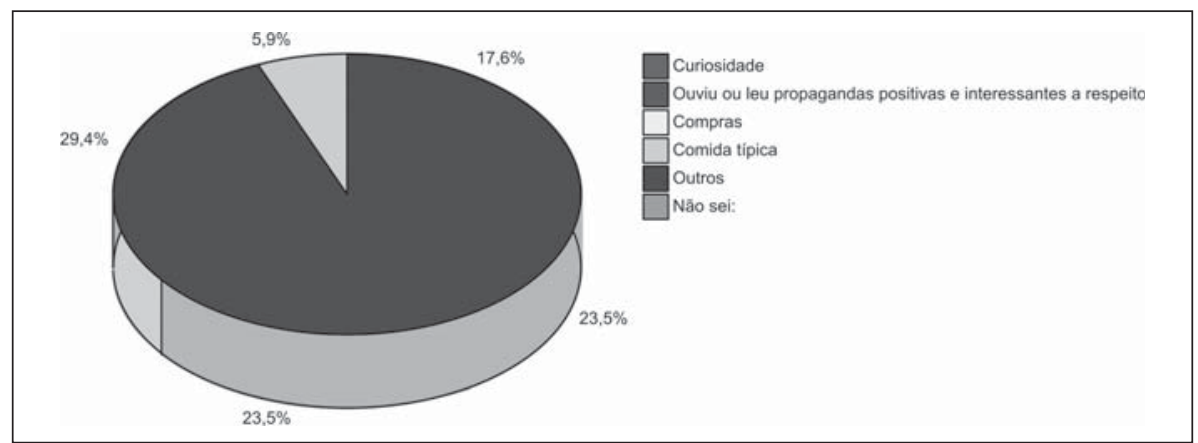

Fonte: pesquisa direta.

Os turistas também disseram sobre o que mais lhes chamou a atenção após ou no decorrer de sua visita à Feira. Foram levantados pontos como a atenção e gentileza por parte dos feirantes ao atender os clientes; o grande número de japoneses; a variedade de produtos ofertados; a comida e o artesanato típicos.

Além dos itens acima citados, os visitantes apontaram o espaço da Feira Central como sendo um ambiente hospitaleiro e agradável. Diante disso, percebese que aqueles que visitam a feira, independente de seus motivos, o fazem pelo prazer de frequentar lugares agradáveis e acolhedores que promovam interação, lazer e prazer.

\subsection{FEIRANTE}

Para grande parte dos feirantes que participaram da pesquisa, a mudança do empreendimento foi positiva (Figura 7), devido ao conforto de não precisarem mais montar e desmontar as antigas barracas, como ocorria antes, a melhor infraestrutura e higiene do local, pois no novo endereço a Feira conta com uma equipe de limpeza mantida pela AFECETUR.

Figura 7: A mudança do endereço da Feira Central para os feirantes.

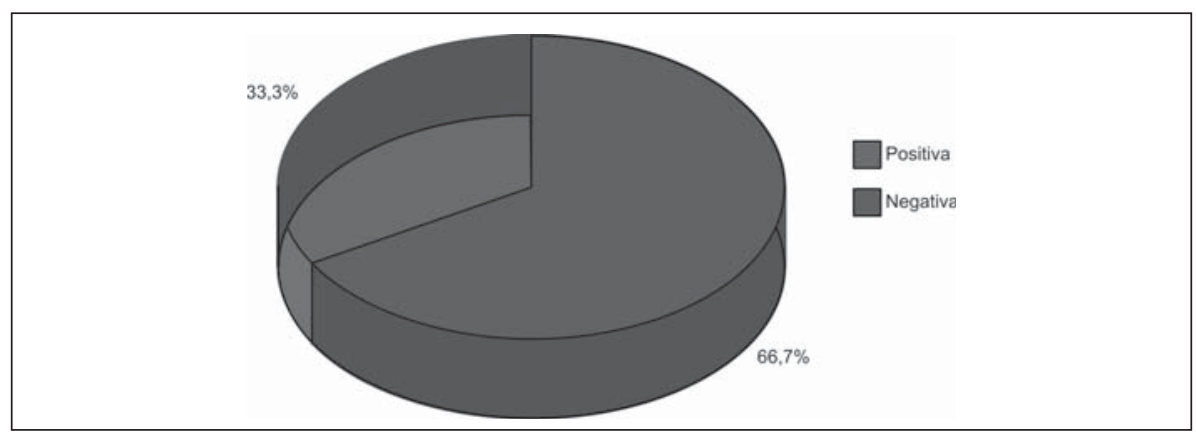

Fonte: pesquisa direta.

Novos Cadernos NAEA •v. 15 n. 2 • p. 85-109 • dez. 2012 
$\mathrm{Na}$ Figura 8, os feirantes atribuíram pesos semelhantes aos itens que, de alguma forma, atribuem valor e representatividade da Feira Central na vida dos mesmos. Contudo, a minoria de $9,8 \%$ justifica sua resposta dizendo que com a mudança de endereço, a Feira perdeu algumas características próprias, como a entrada permitida para todo e qualquer público, inclusive os mais humildes, como os ditos hippies e moradores de rua, apesar da entrada no novo endereço ser gratuita, e, ainda, pela expansão da comercialização dos produtos importados, o que, de fato, descaracteriza simbolicamente o empreendimento.

Os trabalhadores da Feira afirmaram que o empreendimento é importante em suas vidas por ser fonte de renda e lugar de convívio e interação com diversos tipos de pessoas, proporcionando, assim, satisfação no ambiente de trabalho.

Figura 8: A Feira Central para os feirantes.

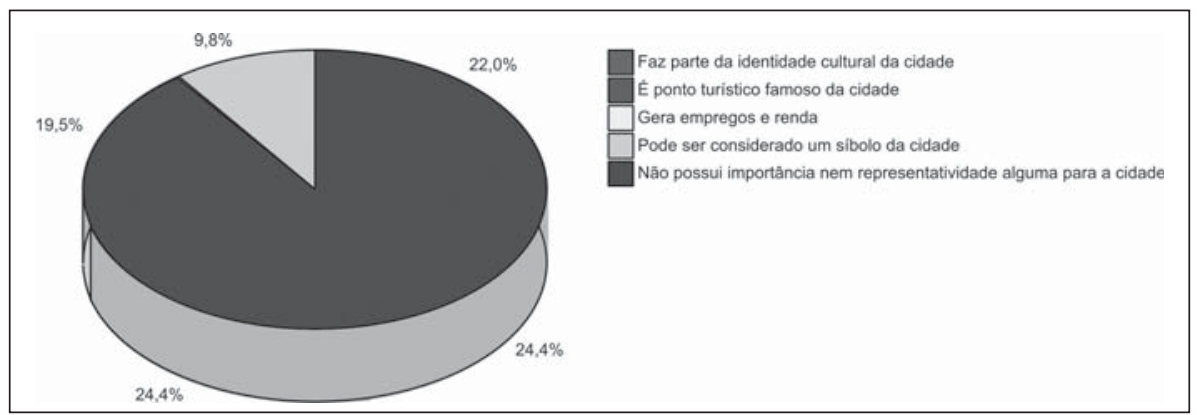

Fonte: pesquisa direta.

\subsection{MORADOR DO ENTORNO}

Os moradores e comerciantes do entorno da Feira Central divergiram em opinião ao se tratar do novo endereço da mesma. De acordo com a Figura 9, percebe-se que quase $67 \%$ dos moradores abordados afirmaram ter sido positiva a mudança da Feira, devido à valorização de cunho financeiro de pontos comerciais e imóveis nas proximidades da mesma, além do aparecimento de novas fontes de renda, por meio de trabalhos informais. 
Figura 9: A mudança do endereço da Feira para os moradores e comerciantes do entorno.

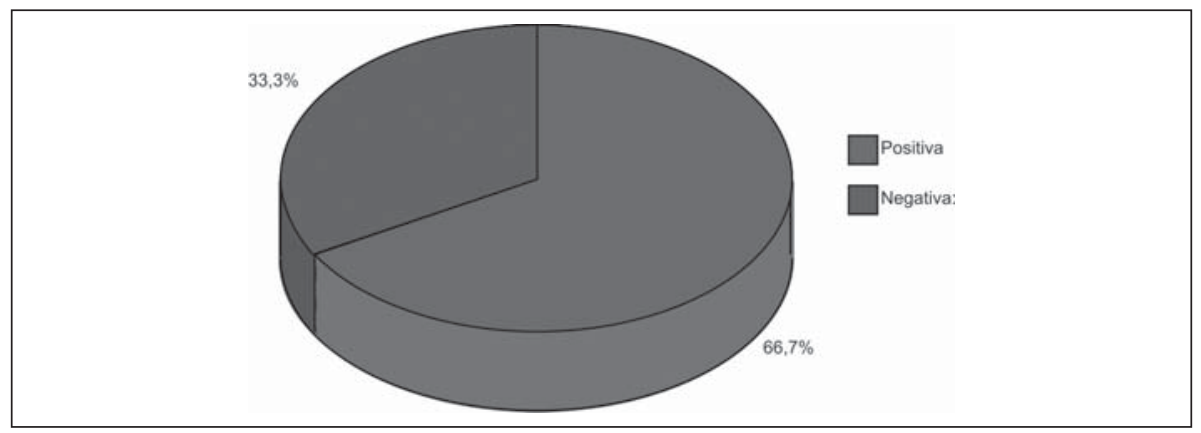

Fonte: pesquisa direta.

Os demais argumentaram ter sido negativa, devido ao grande volume de carros e pessoas que transitam por ali e, consequentemente, o barulho que ocorre nos dias de funcionamento do empreendimento. Com isso, alguns moradores tiveram sua rotina alterada, no que diz respeito a ficarem em casa nos dias de funcionamento da feira - às quartas e sextas-feiras, sábados e domingos - ou até mesmo chegarem em casa mais tarde para não enfrentar o tumulto. Tumulto esse justificado pelo grande volume de pessoas e ao tempo de permanência dos clientes na Feira, o qual, segundo informação obtida por meio da AFECETUR, é de aproximadamente de 5 a 6 horas.

Também houve respostas dizendo que no período da madrugada a segurança no entorno da Feira fica comprometida, pois alguns grupos de jovens ficam bebendo e fumando, sem nenhuma interferência de terceiros, fazendo com que a população do entorno investisse em equipamentos de segurança. De fato, problemas sociais como gangues, drogas e bebida são vistos em grande parte das capitais brasileiras, o que a cidade de Campo Grande não difere em tais aspectos.

Tais problemas sociais citados no parágrafo anterior, presentes no meio urbano, são realmente consideráveis para com a cultura da cidade, e ainda despertam para as questões de omissão e até comodidade por parte daqueles que frequentam, trabalham ou usufruem de qualquer forma do espaço da Feira. Para ilustrar, para Bresciani (2002, p. 30), a intenção de naturalizar os problemas da cidade, ou seja, de reduzi-los a questões técnicas, portanto disciplinares, cai por terra ao ser confrontada com o caráter produtor de cultura das soluções propostas. $\mathrm{O}$ fato descrito merece atenção por parte das autoridades competentes.

$\mathrm{Na}$ Figura 10, percebe-se que os moradores não atribuem significativa representatividade positiva à Feira Central, vendo apenas o empreendimento enquanto ponto turístico da cidade. Apenas uma minoria de 9,1\% se manifestou 
quanto à geração de empregos e renda, demonstrando então aspectos diferentes quanto à territorialidade, em relação aos demais públicos pesquisados.

Atribuir sentimentos relacionados ao empreendimento é uma ação abstrata. Os moradores, mesmo com todos os aspectos negativos aqui citados, demonstraram alguma representatividade positiva quanto à Feira Central. Fator esse que pode ser estimulado, a fim de mostrar que o empreendimento pode ser melhor visto.

Figura 10: A Feira Central para os moradores do entorno.

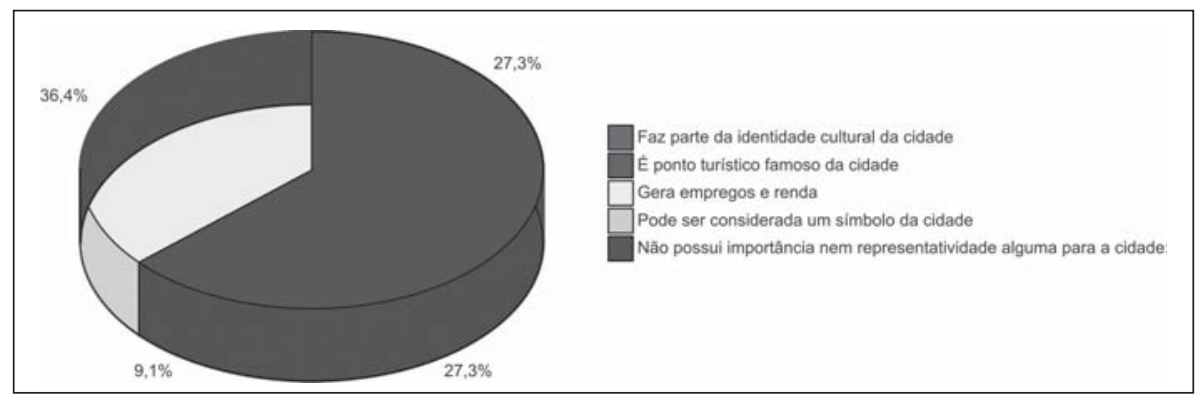

Fonte: pesquisa direta.

\subsection{ALTERAÇÃO NO USO E OCUPAÇÃO DO SOLO}

Por meio das imagens do software Google Earth versão 6.0, entre os anos 2002 a 2009, foi possível a visualização das alterações do uso e ocupação do solo causadas pelo empreendimento.

A Figura 11, registrada em 03/04/2002, mostra o território antes da instalação do empreendimento da Feira Central. Percebe-se que havia uma grande e vasta área destinada aos trilhos e vagões pertencentes à Estação Ferroviária de Campo Grande, a qual foi construída em 1909, porém, ainda ativa para o escoamento de produtos e cargas do estado.

Do lado esquerdo da imagem, percebe-se uma grande área verde, até então inutilizada antes da instalação do empreendimento. Essa área era destinada a pequenos proprietários agricultores. Em frente a esta área, nota-se uma vila pouco povoada, com ruas ainda sem asfalto e a presença relevante de árvores. 
Figura 11: Território ainda não ocupado pelo empreendimento da Feria Central, em 03/04/2002.

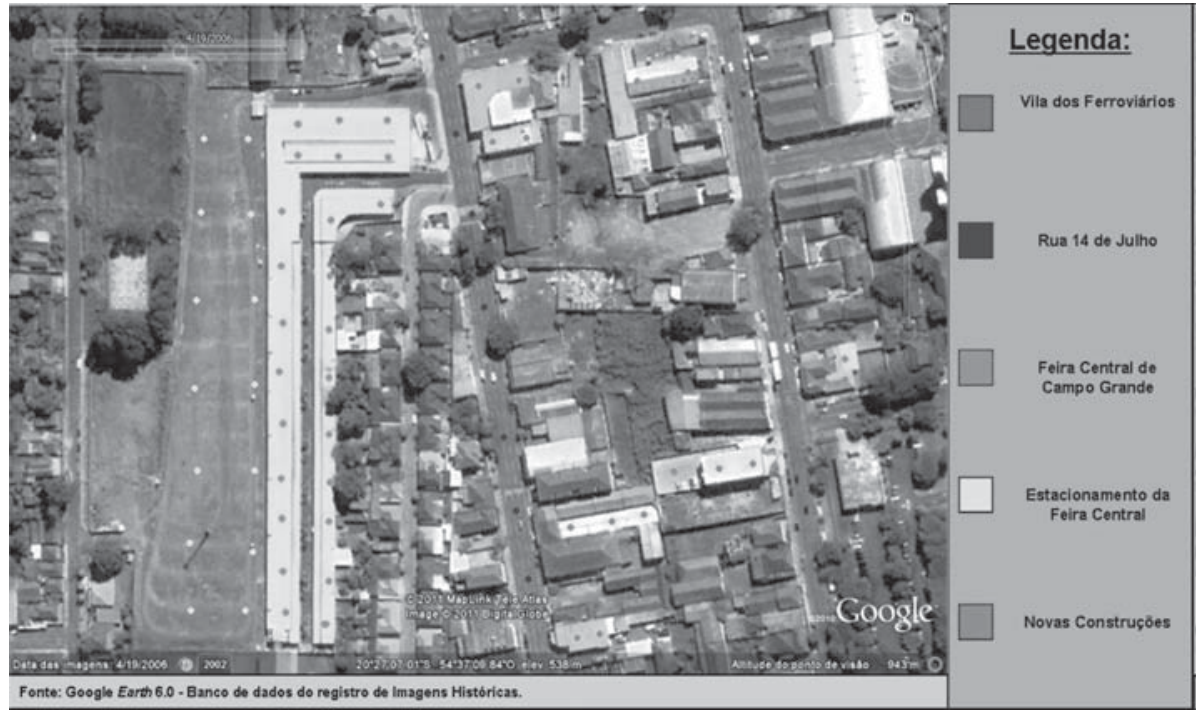

Fonte: Banco de dados do Registro de Imagens Históricas. Disponível em: Google Earth 6.0.

Do lado direito da imagem, visualiza-se a antiga vila dos ferroviários, considerada um patrimônio da cidade, devido a sua importância histórica. Diante disso, é provável que sua estrutura não seja alterada. Contudo, em frente à vila, notam-se casas e construções antigas, com quintais extensos, de área verde não construída, característica de ambientes ditos rurais e de pouco acesso. Porém, esse território já é considerado área central e urbana de Campo Grande, devido ao avanço de investimentos e também da instalação da Feira Central, pois o volume de pessoas que a mesma recebe é significativo para a economia da cidade.

Já a Figura 12, registrada em 19/04/2006, mostra o empreendimento já instalado e algumas alterações inicializadas. A estrutura grande da construção na cor amarela tomou o lugar da área antes inutilizada, seja pelo poder público ou privado. Os trilhos tiveram de ser removidos e a linha férrea realocada e, com isso, houve outras iniciativas para tornar o prédio onde eram vendidas as passagens ferroviárias da cidade, um excelente local para a realização de eventos culturais. 
Figura 12: Território recém-ocupado pelo empreendimento da Feira Central, em 19/04/2006.

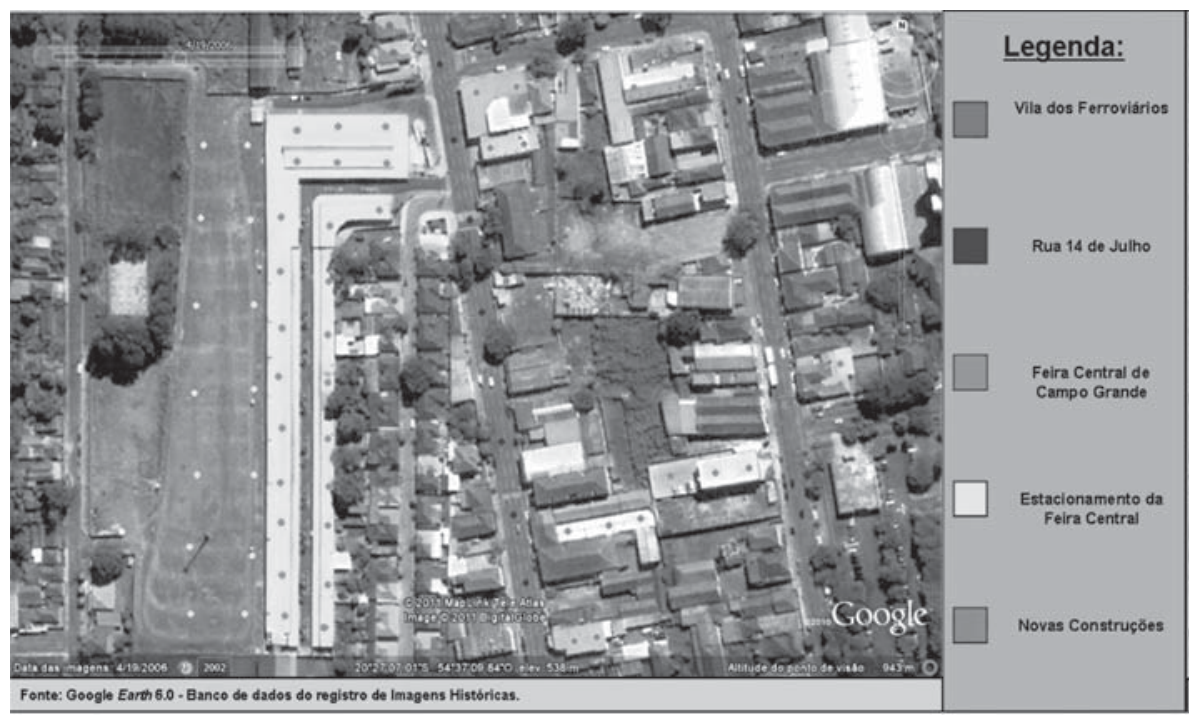

Fonte: Banco de dados do Registro de Imagens Históricas. Disponível em: Google Earth 6.0.

Do lado esquerdo da imagem do ano de 2006, percebe-se que a rua em frente da vila está preparada para ser asfaltada. Diante disso, pode-se afirmar que a instalação do empreendimento possibilitou melhor acesso à comunidade, até então com dificuldades para se deslocar.

Do lado direito da imagem, percebe-se que grande parte das casas já está com quintais menores, com mais construções à frente da Feira Central. Predominam casas e estabelecimentos comerciais. Nota-se que o fluxo de veículos é maior.

Na Figura 13, registrada em 10/08/2009, cinco anos após a instalação do empreendimento da Feira Central, nota-se que a vila dos ferroviários permanece igual, devido ao seu valor histórico-cultural, porém, a estrutura do entorno está bem modificada, com mais construções e maior fluxo de pessoas e veículos. Contudo, percebe-se que a arborização não foi totalmente exterminada, mas sim, mantida em parte. 
Figura 13: Território ocupado pelo empreendimento da Feira Central, em 10/08/2009, após cinco anos de sua instalação.

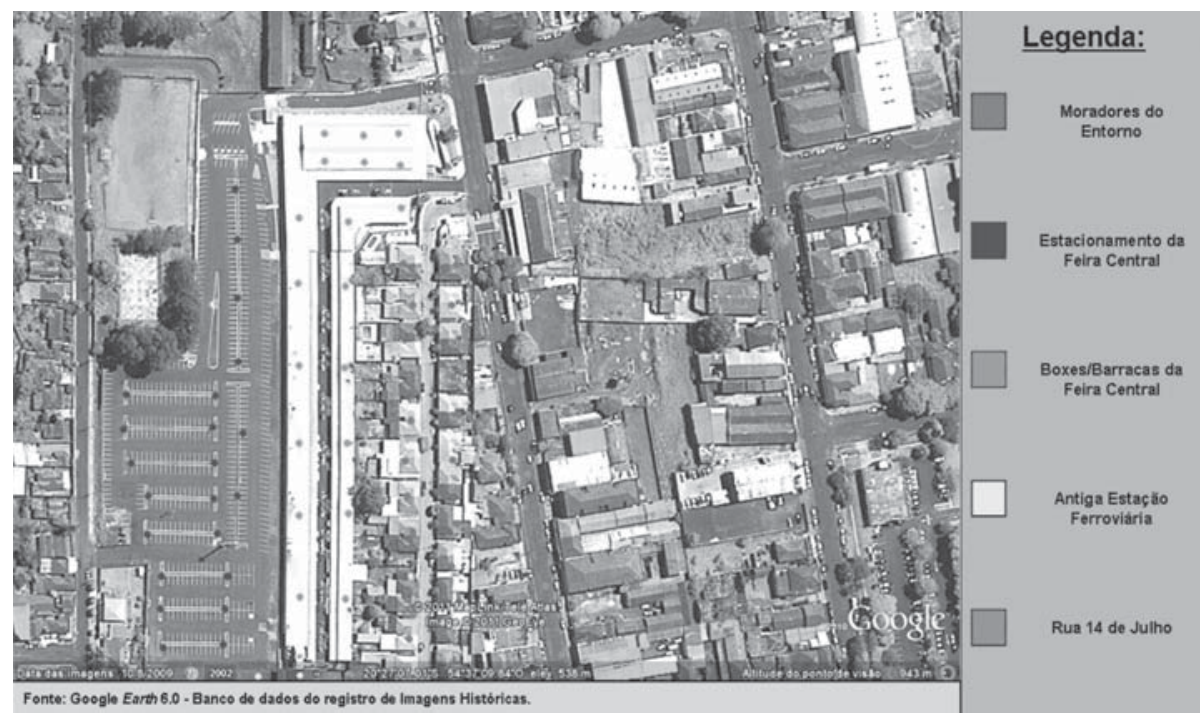

Fonte: Banco de dados do Registro de Imagens Históricas. Disponível em: Google Earth 6.0.

A partir dos resultados apresentados, percebeu-se que o fato da mudança da Feira Central, no ano de 2004, possibilitou mudanças na vida de todos os públicos abordados pela pesquisa, porém, um deles merece destaque - os feirantes. De acordo com os argumentos advindos dos feirantes, é pertinente salientar as alterações na sua dinâmica e a perda de algumas características, como a criação de uma Associação de Feirantes, a instituição de alvarás, a elaboração de regimento interno imposto a esse público; o desaparecimento de alguns alimentos antes comercializados na feira e a não permissão de determinados públicos.

De acordo com os apontamentos, é comprovado que a relação da feira como símbolo de cultura para os feirantes foi abalada devido às alterações ocorridas. De fato, a representatividade do empreendimento, do ponto de vista desse público, é comercializável, em parte, com a justificativa de atrair e promover a Feira Central de Campo Grande.

Para os demais públicos, o empreendimento é um espaço para diversas ações e acontecimentos, como encontro com família e amigos, comercialização de produtos regionais, apreciação de comida típica e da cultura japonesa enraizada e presente na Feira. Demonstraram que a feira possui representatividade positiva em suas vidas, além de fazer parte da cultura da cidade. 


\section{CONSIDERAÇÕES FINAIS}

Os vários aspectos levantados e discutidos nesta pesquisa apontam que a Feira Central de Campo Grande é, primeiramente, um tema vasto a ser estudado. Suas diversas características envolvem e influenciam as vidas das pessoas que com ela se relacionam, seja pela cultura, pela representatividade, simbologia, e ainda pelas consequências de sua desterritorialização e reterritorialização.

A identidade cultural expressada pela Feira Central de Campo Grande é significativa e importante para os variados públicos abordados nesta pesquisa. As pessoas que por variados motivos se relacionam com o empreendimento, atribuem a ele sentimentos mais positivos do que negativos. Percebeu-se, por meio dos questionários aplicados, que com a mudança de endereço, muitas pessoas afirmaram que o empreendimento perdeu algumas características relevantes, como o fato de não ser mais nômade, e sim fixa em um espaço somente seu. Isso é perceptível a partir dos limites da propriedade do empreendimento, pois o mesmo é cercado com portões e com a presença constante de seguranças.

O impacto cultural do empreendimento no período analisado foi demonstrado como algo importante para os públicos abordados, exceto para os feirantes, os quais argumentaram que os aspectos culturais foram, de certa forma, modificados e/ou adaptados, mediante a nova infraestrutura oferecida e proporcionada pela Prefeitura Municipal.

Sua importância quanto à territorialidade, expressada pelos diversos públicos abordados, poderá ser utilizada economicamente em prol da cidade. É possível melhorar a divulgação e a capacidade turística da cidade mediante a Feira Central, pois a representatividade, simbologia e importância atribuídas a ela, na vida dos campo-grandenses, fazem com que a mesma possa fazer parte, de fato, da identidade cultural da cidade e, com isso, obter benefícios tanto econômicos quanto sociais.

A partir dessa nova territorialidade que ocorreu devido à mudança do local da Feira no período pesquisado, detectaram-se novas estruturas físicas e distribuição do fluxo de tráfego. Essas novas ramificações no uso e ocupação territorial provocadas pelo empreendimento ocasionaram mudanças no espaço urbano de Campo Grande (MS).

A análise espaço-temporal, realizada no período de 2002 a 2009, sobre o novo território ocupado pela Feira Central de Campo Grande é significativa e importante para os variados atores envolvidos e atingidos pelo processo. Os aspetos percebidos, que norteiam a reconstrução de um novo território, foram mais pontos positivos do que negativos. 
Percebeu-se, por meio das imagens, que a importância do empreendimento é relevante, devido ao crescimento econômico provocado após a sua instalação à região até então desvalorizada e inutilizada. Diante das imagens, concluiu-se que grande parte da arborização existente foi mantida, além de trazer novos investimentos e oportunidades de emprego, apresentando maior valorização dos imóveis no entorno. É necessário mais investimentos para que se aumente a capacidade de suporte da Feira Central, devido ao grande volume de pessoas que visitam o empreendimento, pois a região em questão deve ser estimulada ao crescimento e desenvolvimento econômico.

\section{REFERÊNCIAS}

BRASIL. Mato Grosso do Sul. Secretaria de Estado de Meio Ambiente, do Planejamento, da Ciência e Tecnologia. Dados Estatísticos de Mato Grosso do Sul 2009: ano base: 2008. Campo Grande, 2009. 101 p.

BEZERRA, A. C. A. et. al. Festa e Identidade: a busca da diferença para o mercado da cidade. In: ARAÚJO, F. G. B.; HAESBAERT, R. (Orgs.). Identidades e Territórios: questões e olhares contemporâneos. Rio de Janeiro: Access, 2007. $136 \mathrm{p}$.

BRESCIANI, M. S. Cidade e História. In: OLIVEIRA, L. L. (Org.). Cidade: história e desafios. Rio de Janeiro: FGV, 2002. P. 16- 33.

CASTILHO, M. A.; CHAPARRO, Y.L. A reterritorialização do sagrado no contexto urbanístico de Campo Grande - MS. Revista Brasileira de História das Religiões, Maringá, v. 1, n. 3, p. 381-395, jan. 2009.

COSTA, B. P. As relações entre os conceitos de território, identidade e cultura no espaço urbano. In: ROSENDAHL. Z; CORREAA, R. L. (Orgs.). Geografia: temas sobre cultura e espaço. Rio de Janeiro: EdUERJ, 2005. p. 79-111.

DIÁRIO OFICIAL de Campo Grande - DIOGRANDE. Ano IX - nº 2.101 quarta-feira, 19 de julho de 2006. Disponível em: www.prefeituradecampogrande. com.br/.../ downloadFile.php. Acesso em: 19 set. 2010.

GOOGLE EARTH: Aplicativo de mapas, 6.0. Santa Clara: Google Inc., 2006. HAESBAERT, R. O Mito da Desterritorialização: do "Fim dos Territórios à multiterritorialidade. Rio de Janeiro: Bertrand Brasil, 2004.

IANNI, O. A Sociedade Global. Rio de Janeiro: Civilização Brasileira, 1992. $191 \mathrm{p}$. 
JORNAL O VERBO - Notícias Cristãs. Igreja Universal Inaugura Templo Maior no Sábado em Campo Grande/MS. 12 de Fevereiro de 2008. Disponível em: http://www.overbo.com.br/portal/2008/02/12/5837/. Acesso em: 16 set. 2010.

LAKATOS, E. M.; MARCONI, M. de A. Fundamentos de Metodologia Científica. São Paulo: Atlas, 2009. 315 p.

LE GOFF, J. História e Memória. São Paulo: UNICAMP, 1992. 475 p.

LIMA FILHO, D. de O. Centro Comercial Planejado ou Centro Comercial Não Planejado? A Opinião dos Consumidores da Feira Livre. In: ENCONTRO NACIONAL DE ENGENHARIA DA PRODUÇÃO, 28, 2008. Rio de Janeiro. Anais... Rio de Janeiro, 2008. 12 p.

MARTINS, J. de S. A chegada do estranho. São Paulo: Hucitec, 1993. 179 p.

MARQUES, Rui Cunha. Sobá: Patrimônio Imaterial de Campo Grande/MS. Revista Recanto das Letras, Campo Grande, jul. 2009.

MIDIAMAXNEWS - O Jornal Eletrônico de Mato Grosso do Sul. Megatemplo Traduz Ostentação da Igreja Universal. 12 de Fevereiro de 2008. Disponível em: <http://carlosafqueiroz.blogspot.com/2008/02/brasil-ms-megatemplotraduz-ostentao-da.html>. Acesso em: 16 set. 2010.

OLIVEIRA, R. A. de. Histórias e Tradições - Comunidade Imigrante Japonesa Várzea Alegre. Campo Grande: UNIDERP, 2006. 82 p.

RAFFESTIN, C. Por uma geografia do poder. São Paulo: Ática, 1993. 270 p.

RODRIGUES, C. H.; FORATO, S. Feira Central: o rumo de uma cultura. Campo Grande: UNIDERP, 2002. 23 p.

SANTOS, M.; SILVEIRA, M. L. O Brasil: Território e Sociedade no Início do Século XXI. 10. ed. Rio de Janeiro: Record, 2008. 473 p.

SILVA, V. F. da. Proposta de revitalização da Feira Central para melhor desenvolvimento do turismo local. Campo Grande: UNIDERP, 2003. 63 p.

SPHINX. Sistema para pesquisa e análise de dados, 5.0. Canoas: Sphinx Brasil. 2005. 1 CD-ROM.

TEIXEIRA, R. Cultura de Okinawa: sucursal Campo Grande. Campo Grande/ MS, 2006. Disponível em: http://www.overmundo.com.br/overblog/culturade-okinawa-sucursal-campo-grande. Acesso em: 15 out. 2010. 


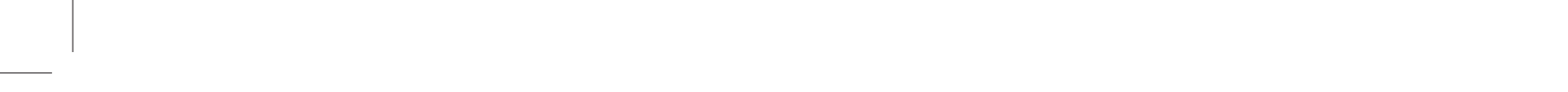

